\title{
Homo reciprocans: survey evidence on behavioural outcomes
}

Citation for published version (APA):

Dohmen, T. J., Falk, A., Huffman, D., \& Sunde, U. (2009). Homo reciprocans: survey evidence on behavioural outcomes. The Economic Journal, 119(536), 592-612. https://doi.org/10.1111/j.14680297.2008.02242.x

Document status and date:

Published: 01/01/2009

DOI:

10.1111/j.1468-0297.2008.02242.x

Document Version:

Publisher's PDF, also known as Version of record

\section{Please check the document version of this publication:}

- A submitted manuscript is the version of the article upon submission and before peer-review. There can be important differences between the submitted version and the official published version of record.

People interested in the research are advised to contact the author for the final version of the publication, or visit the DOI to the publisher's website.

- The final author version and the galley proof are versions of the publication after peer review.

- The final published version features the final layout of the paper including the volume, issue and page numbers.

Link to publication

\footnotetext{
General rights rights.

- You may freely distribute the URL identifying the publication in the public portal. please follow below link for the End User Agreement:

www.umlib.nl/taverne-license

Take down policy

If you believe that this document breaches copyright please contact us at:

repository@maastrichtuniversity.nl

providing details and we will investigate your claim.
}

Copyright and moral rights for the publications made accessible in the public portal are retained by the authors and/or other copyright owners and it is a condition of accessing publications that users recognise and abide by the legal requirements associated with these

- Users may download and print one copy of any publication from the public portal for the purpose of private study or research.

- You may not further distribute the material or use it for any profit-making activity or commercial gain

If the publication is distributed under the terms of Article $25 \mathrm{fa}$ of the Dutch Copyright Act, indicated by the "Taverne" license above, 


\title{
HOMO RECIPROCANS: SURVEY EVIDENCE ON BEHAVIOURAL OUTCOMES*
}

\author{
Thomas Dohmen, Armin Falk, David Huffman and Uwe Sunde
}

\begin{abstract}
This article complements the experimental literature that has shown the importance of reciprocity for behaviour in stylised labour markets or other decision settings. We use individual measures of reciprocal inclinations in a large, representative survey and relate reciprocity to real world labour market behaviour and life outcomes. We find that reciprocity matters and that the way in which it matters is very much in line with the experimental evidence. In particular, positive reciprocity is associated with receiving higher wages and working harder. Negatively reciprocal inclinations tend to reduce effort. Negative reciprocity increases the likelihood of being unemployed.
\end{abstract}

Reciprocity is an in-kind response to friendly or hostile acts. Homo economicus would never engage in reciprocal behaviour, where it does not advance material self-interest. An alternative model is homo reciprocans, for whom reciprocal behaviour is driven by reciprocal motivations: direct utility value is placed on rewarding or punishing (Rabin, 1993; Falk and Fischbacher, 2006). Conceptually, one can distinguish between positive reciprocity, the degree to which an individual rewards kind actions, and negative reciprocity, the extent to which the individual punishes unkind actions. Positive reciprocity has been demonstrated in experimental settings where contracts are incomplete and workers reciprocate generous wages with high effort, even though there is no way to enforce contracts (Fehr et al., 1993; Brown et al., 2004). Positive reciprocity can also explain why people reward trust in the well-known trust game (Berg et al., 1995; Falk and Zehnder, 2007). Negative reciprocity is relevant in bargaining games, for example in terms of willingness to reject unfair offers even at a personal cost (Güth et al., 1982; Camerer and Thaler, 1995), and for willingness to punish others who violate norms of cooperation or fairness in public goods games (Fehr and Gächter, 2000; Carpenter and Seki, 2005).

While experimental evidence has shown the behavioural relevance of reciprocity in laboratory settings, there is less evidence for the role of reciprocity outside the laboratory. The experimental approach is valuable for the ability to provide closely controlled measures of behaviour. For example, relevant payoffs and information conditions are controlled by the experimenter, who can vary the one-shot versus repeated nature of the game, to distinguish between reciprocal behaviour based on reciprocal motivation or based on strategic considerations. In this article we take an alternative approach, using individual measures of reciprocal inclinations in a large representative survey and relate these measures to actual labour market behaviour and other life outcomes. A key advantage of survey measures is the ability to study reciprocity for a large representative subject pool. Paid experiments are typically restricted

\footnotetext{
* We thank the editor, two anonymous referees, Adrian Non, and participants of various conferences and seminars for their helpful comments. Financial support from the German Research Foundation (DFG) through SFB/TR 15 and the Research Network 'Flexibility in Heterogeneous Labour Markets', as well as from the European Research Council (ERC) Starting Grant is gratefully acknowledged.
} 
to much smaller samples of college students. A large survey also affords the statistical power necessary to investigate how reciprocity is related to various behaviours and life outcomes. As is always the case in empirical studies without the luxury of natural experiments, the evidence takes the form of correlations. However, even correlations are interesting in this case, given that the experimental literature provides directed hypotheses that can be falsified by using correlations. Furthermore, it is difficult to argue for reverse causality for most of the outcomes we consider. For example, it is unlikely that working overtime makes someone more positively reciprocal. Finally, we use longitudinal data and show that reciprocal inclinations predict not only current but also future economic outcomes, such as unemployment or life-satisfaction. This is suggestive of a causal relationship because future outcomes are unlikely to affect current measurement of reciprocity.

We first investigate the prevalence of positive and negative reciprocal inclinations in the population and test whether these are part of the same underlying trait or instead reflect separate traits. Theoretically, reciprocity has typically been assumed to be a single trait, i.e., someone who is strongly inclined to reward kind actions is assumed to be someone who is also strongly inclined to punish unkind actions. In the model of Falk and Fischbacher (2006), for example, a single parameter $\rho$ is assumed to capture willingness to reciprocate regardless of whether reciprocation involves punishment or reward. If this assumption is approximately correct, one would expect to find a strong correlation between the degree of positive and negative reciprocity for an individual. If there is little correlation, it suggests that these are actually separate traits and that theories of reciprocity should incorporate separate parameters for positive and negative reciprocity.

One of the main findings from the experimental literature on reciprocity concerns worker behaviour in stylised labour markets. Numerous studies, both theoretical and empirical, have argued that positive reciprocity can explain why workers perform even when they have ample opportunity for shirking (Akerlof, 1982; Fehr et al., 1993; Bewley, 1999; Fehr and Falk, 1999). In other words, it is hypothesised that there is a positive correlation between the strength of a worker's positively reciprocal inclinations and the extent to which the worker responds to a generous wage by working hard. To the best of our knowledge this article is the first to test this claim on the basis of a large survey. ${ }^{1}$ We measure work effort using data on overtime hours worked. We show that positively reciprocal inclinations are positively associated with working overtime while the reverse holds for negative reciprocity. Moreover we use a survey question that asks whether a worker thinks his wage is fair and test whether reciprocity affects the way the worker responds to having a fair or unfair wage. Positive reciprocity is hypothesised to determine the positive effort response to a fair wage. The results are strikingly consistent with this hypothesis, lending support to the generalisability of laboratory findings.

We next consider how employers treat workers depending on workers' reciprocal inclinations. Experimental evidence suggests that in settings with incomplete contracts, firms increase wages as they learn that a worker is willing to reciprocate with higher

\footnotetext{
1 Interesting related evidence is provided by Clark et al. (2006), who show that a survey question about willingness to put in effort on the job above and beyond the call of duty is positively correlated with the income paid by the employer.
}

(C) The Author(s). Journal compilation (C) Royal Economic Society 2009 
effort. For example, Brown et al. (2004) show that successful labour relationships under incomplete contracts begin with a period of gradually increasing wages and worker effort, i.e., a buildup of trust and reciprocal interactions. For workers who are not positively reciprocal, the firm does not have an incentive to increase the wage. To the extent that firms can learn about worker types, we should thus observe that positively reciprocal workers tend to receive higher wages. On the other hand, there are reasons to think that firms will not discriminate against negatively reciprocal workers with lower wages. Indeed, the more negatively reciprocal a worker is, the more dangerous it is to pay a low wage for fear of triggering sanctions. Rather than cut the wage of a negatively reciprocal worker, it may be better to dismiss the worker, as argued by Bewley (1999). This would imply a role for negative reciprocity along the margin of employment versus unemployment: negatively reciprocal types should be more likely to be unemployed. Increasing positive reciprocity, on the other hand, should be associated with increasing probability of being employed, consistent with experimental evidence on the benefits of positive reciprocity for sustaining long-term relationships (Brown et al., 2004). These predictions are borne out by the data.

We then turn to the question of whether reciprocal inclinations tend to foster individual success. Since reciprocal individuals are willing to reward and sanction fair or unfair behaviour even if this is costly, one might speculate that such behaviour could lead to a strategic disadvantage, because of resources 'wasted' on rewards and sanctions. On the other hand, it is known from evolutionary game theory that if types can be signalled it can be an advantage to credibly signal that one is willing to punish unfair behaviour or to reward fair treatments. For example, firms that expect reciprocal actions by their workers may have a reason to pay higher wages or to treat workers with respect (Akerlof, 1982; Bewley, 1999). Likewise, teams consisting of a sufficient number of reciprocators will find it easier to enforce the voluntary provision of public goods, which may result in higher efficiency (Fehr and Gächter, 2000). Assessing the implications of reciprocity requires evidence on life outcomes from outside of the laboratory.

Our analysis of wage and unemployment outcomes provides a first piece of evidence on the success of reciprocity as an individual trait. We investigate the issue further by taking a broader perspective on success, showing that reciprocal types have a larger number of close friends, and a higher degree of subjective well-being. The latter finding is particularly relevant because many social scientists agree that happiness is an important goal of human life and perhaps best summarises success and achievement in a general way (Frey and Stutzer, 2002).

In sum our results show the economic relevance of reciprocity and complement previous laboratory findings by providing strong corroboration for the relationships between reciprocity and labour market outcomes typically observed in more stylised experimental settings. Moreover, we are able to address the question how reciprocity translates into life success, and find that positively reciprocal people have more close friends and a higher overall level of life satisfaction. In this sense, Homo Reciprocans - in the positive domain - is in fact more successful than his or her non-reciprocal fellows. On a more general level our results show that non-cognitive skills, such as reciprocity, can have strong and systematic effects on economic outcomes.

The rest of the article is organised as follows. In the next Section we describe the data, and provide descriptive statistics regarding the reciprocity measures. Section 2 (C) The Author(s). Journal compilation (C) Royal Economic Society 2009 
explores consequences of reciprocity: worker effort, wage levels and employment as well as measures of individual success, in terms of number of close friends and happiness. Section 3 concludes.

\section{Data}

Our data come from the German Socio-Economic Panel Study (SOEP). The SOEP is a representative panel survey of the resident population of Germany; for a detailed description, see Wagner et al. (1993) and Schupp and Wagner (2002). The initial wave of the survey was conducted in $1984 .^{2}$ The SOEP surveys the head of each household in the sample, but also gives the full survey to all other household members over the age of 17. Respondents are asked for a wide range of personal and household information, and for their attitudes on assorted topics, including political and social issues.

The 2005 wave of the survey, which includes 21,105 individuals from 11,453 households, contains questions about positive and negative reciprocity. These questions are based on the measure developed by Perugini et al. (2003) and were included in the SOEP for the first time. Respondents were asked to indicate on a 7-point scale how well each of the following six statements (translated from German) applies to them personally:

(1) If someone does me a favour, I am prepared to return it;

(2) If I suffer a serious wrong, I will take revenge as soon as possible, no matter what the cost;

(3) If somebody puts me in a difficult position, I will do the same to him/her;

(4) I go out of my way to help somebody who has been kind to me before;

(5) If somebody offends me, I will offend him/her back;

(6) I am ready to undergo personal costs to help somebody who helped me before. ${ }^{3}$

An answer of 1 on the scale means: 'does not apply to me at all' and choosing 7 means: 'applies to me perfectly'. Questions (1), (4) and (6) ask about positive reciprocity, while questions (2), (3) and (5) ask about negative reciprocity. Also, two of the questions ask explicitly whether the respondent would incur costs in order to be negatively reciprocal (question 2) or positively reciprocal (question 6). In total, 20,774 individuals responded to all six reciprocity measures. ${ }^{4}$ It is noteworthy that the measures do not mention strategic reasons for behaving reciprocally. Therefore it seems likely that respondents report reciprocity that reflects a taste for reciprocal behaviour, as is assumed in the homo reciprocans model. Thus, we hypothesise that our results on behavioural outcomes will turn out to be consistent with findings from laboratory experiments that typically measure reciprocity in one-shot, non-strategic settings. A disadvantage of the survey measures, however, is that there is less control and there is always a role for

\footnotetext{
${ }^{2}$ The panel was extended to include East Germany in 1990, after reunification. For more details on the SOEP, see http://www.diw.de/gsoep/.

${ }^{3}$ German versions of all six questions are available online, at the following web site: http://www.diw.de/ deutsch/sop/service/fragen/fr2005/personen_2005.pdf. The word 'offend' is translated into German as 'beleidigen', which has a strongly negative connotation.

${ }^{4}$ The response rate is very high, and quite similar, across the individual questions. For each question, we observe responses from at least $99 \%$ of the 21,105 individuals in the sample.
} 
responders to interpret the measures in their own way. This means that it is not perfectly possible to disentangle reciprocal motivation from reciprocal behaviour.

Based on experimental evidence, we would predict substantial heterogeneity in reciprocal inclinations. Although a substantial fraction of subjects in experiments are observed to engage in reciprocal behaviour, the degree of reciprocity varies widely and a non-trival proportion typically shows no signs of reciprocal behaviour at all (Fehr and Gächter, 2000). ${ }^{5}$

Figure 1 shows the distributions of answers to each of the six different reciprocity measures. A first observation is that most people indicate some degree of positive reciprocity. For each of the three positive reciprocity statements, less than $5 \%$ say that the statement does not apply to them at all. The modal response is a 6 or 7 for all three statements, indicating that a substantial number of people report that the statement applies to them almost perfectly. As expected there is substantial heterogeneity, however, with a fraction ranging from about $15 \%$ to $40 \%$ stating some other, intermediate level of agreement, depending on the measure. For negative reciprocity, the modal response is 1 or 2 , corresponding to zero or only mild negatively reciprocal inclinations. However, compared to positive reciprocity, there is even greater variance within each measure. For each of the questions, a substantial number of individuals, roughly $50 \%$, report an intermediate level of agreement that they are negatively reciprocal, from 3 to 5 . There is also a non-trivial fraction, roughly $10 \%$ for each question, who choose a 6 or 7 , indicating almost complete agreement with even the strongest statements about negative reciprocity. Thus, it appears that some degree of reciprocal inclinations is pervasive in the population, particularly for positive reciprocity, but that there is heterogeneity.

Agreement with positive reciprocity statements appears to be decreasing in the level of the cost associated with supporting others mentioned in the question. This is consistent with essentially all theoretical models of reciprocity, which typically assume that an individual cares about own material well-being (Rabin, 1993; Falk and Fischbacher, 2006). It is also predicted based on laboratory evidence, which shows that willingness to reciprocate decreases in the costs of doing so (Quervaine et al., 2004; Falk et al., 2005). For example, the top panel for positive reciprocity shows that more than $60 \%$ fully agree that they are willing to return a favour, but this drops to around $35 \%$ in the middle panel, where the statement mentions having to go out of one's way, and to only $22 \%$ in the bottom panel, for the statement that explicitly mentions having to undergo personal costs. For negative reciprocity, there is less evidence that willingness to reciprocate depends on the costs associated with punishment; the distribution is quite similar across the three different statements. This could indicate that people are less sensitive to costs when it comes to punishing, or that the different statements also involve differences in the psychic rewards for punishing. ${ }^{6}$

\footnotetext{
${ }^{5}$ Understanding what proportion of the general population has reciprocal inclinations is useful, given that the prevalence of reciprocal types in the population as well as market institutions are crucial in determining whether reciprocal or nonreciprocal behaviour dominates in the market equilibrium (Falk and Fischbacher, 2006).

${ }^{6}$ For example, the statement that involves taking revenge at any cost also states that this is in response to a serious wrong. The statement about reciprocating an insult does not mention a cost but redressing an insult may be less important than responding to a serious wrong, potentially explaining why willingness to reciprocate is similar in these two situations.
}

(C) The Author(s). Journal compilation (C) Royal Economic Society 2009 

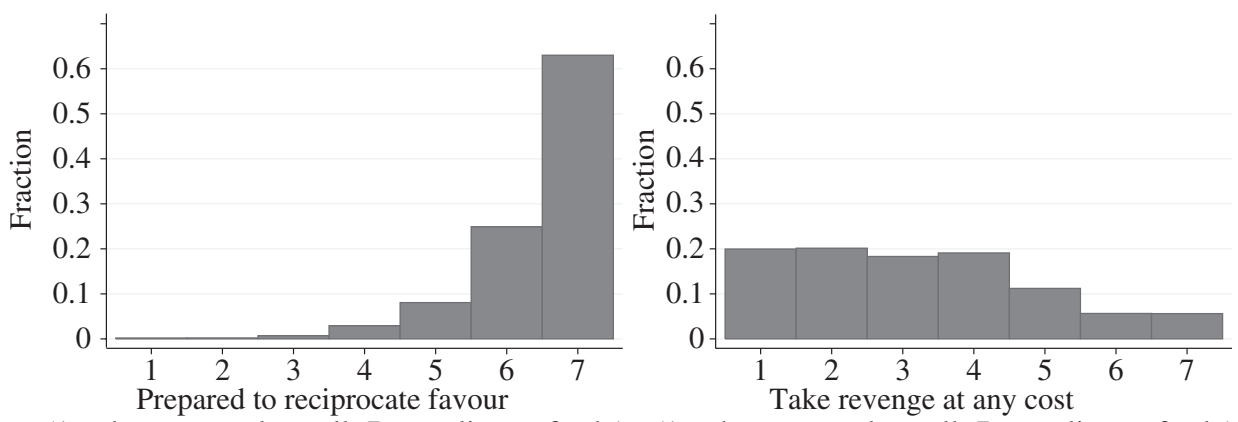

$(1=$ does not apply at all; $7=$ applies perfectly $)$
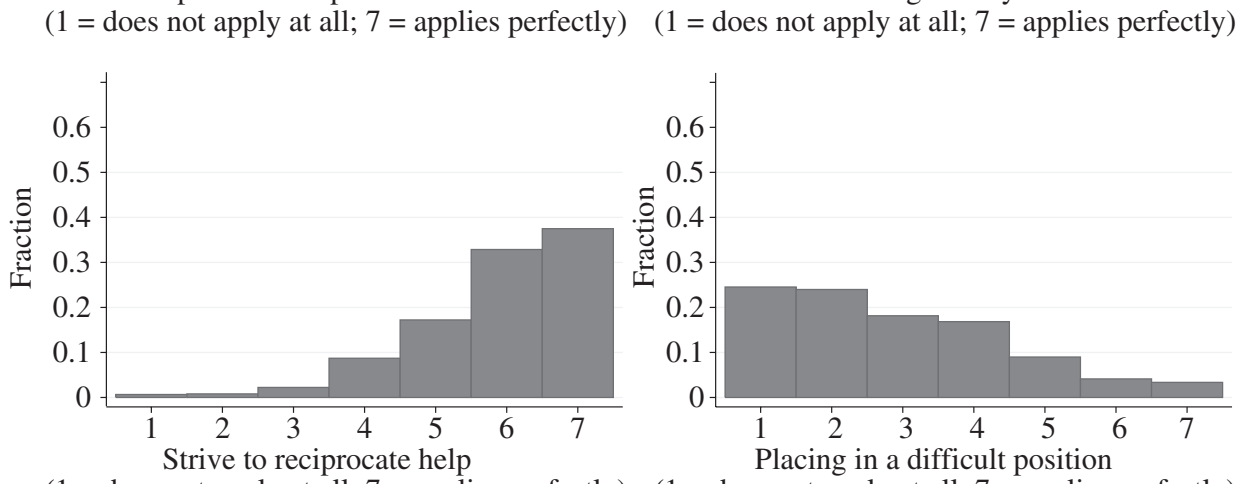

$(1=$ does not apply at all; $7=$ applies perfectly $)$
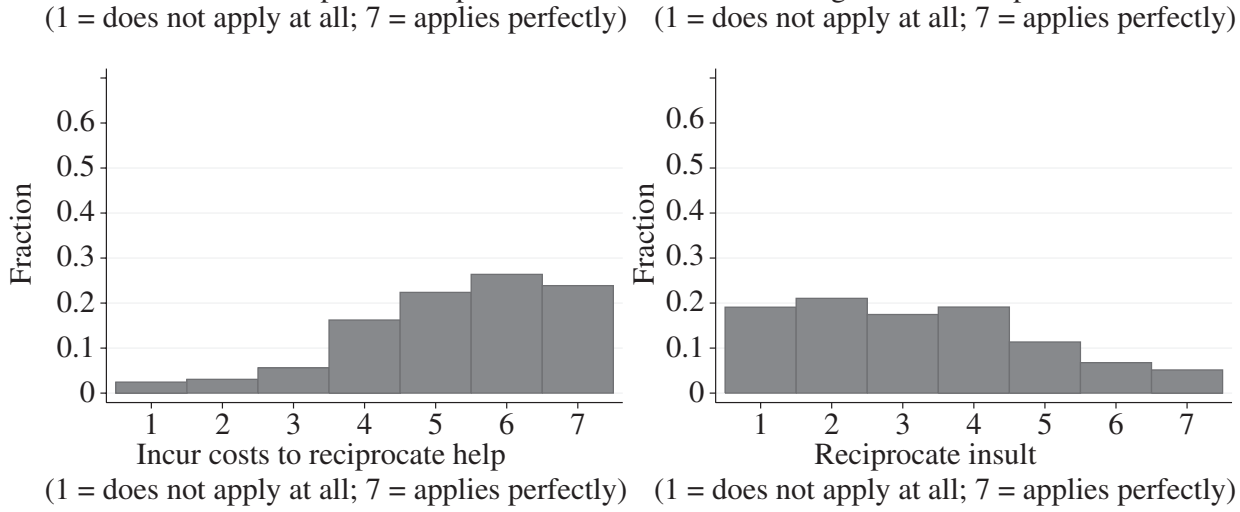

Fig. 1. Distribution of Reciprocity

Notes. The histograms are based on answers to questions about reciprocal inclinations that were asked in the 2005 wave of the German Socio-Economic Panel Study (SOEP). Respondents were asked to indicate on a 7-point scale how well each of the following six statements (translated from German) applies to them personally: (1) If someone does me a favour, I am prepared to return it; (2) If I suffer a serious wrong, I will take revenge as soon as possible, no matter what the cost; (3) If somebody puts me in a difficult position, I will do the same to him/her; (4) I go out of my way to help somebody who has been kind to me before; (5) If somebody offends me, I will offend him/her back; (6) I am ready to undergo personal costs to help somebody who helped me before. An answer of 1 on the scale means: 'does not apply to me at all' and choosing 7 means: 'applies to me perfectly'. The histograms show the distributions of responses to each of the six reciprocity measures of the 20,774 individuals who responded to all six reciprocity measures. Positive reciprocity measures (responses to questions (2), (3) and (5)) are shown in the left-hand panels, negative reciprocity measures (responses to questions (1), (4) and (6)) in the right-hand panel. 
In order to get a sense of individuals' overall tendency to be positively or negatively reciprocal, we average responses over the three positive and negative statements, respectively. Figure 2 shows the distributions of these averages. ${ }^{7}$ The qualitative message is unchanged by collapsing the individual measures of positive and negative reciprocity in this way. Most people report substantial inclination to be positively reciprocal but there is still variation. For negative reciprocity there is more variation, such that many people report only weak agreement with negative reciprocity statements on average but a

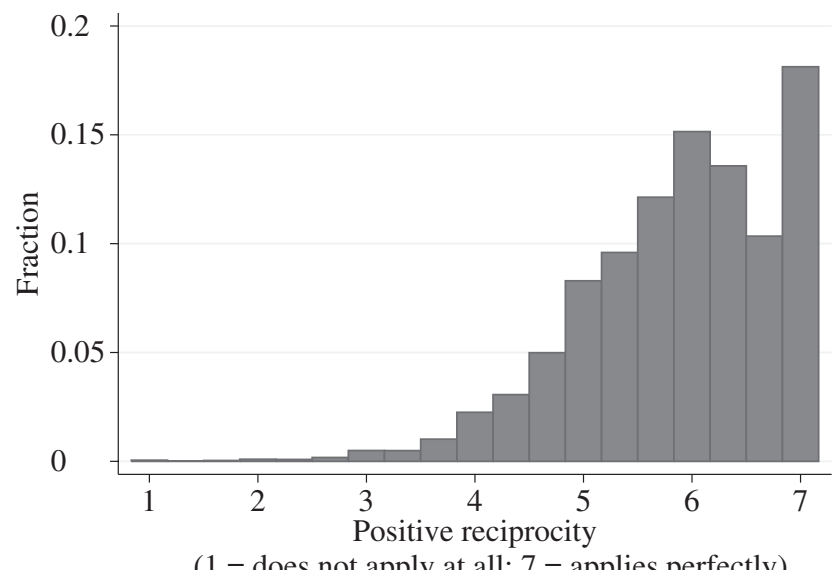

$(1=$ does not apply at all; $7=$ applies perfectly $)$

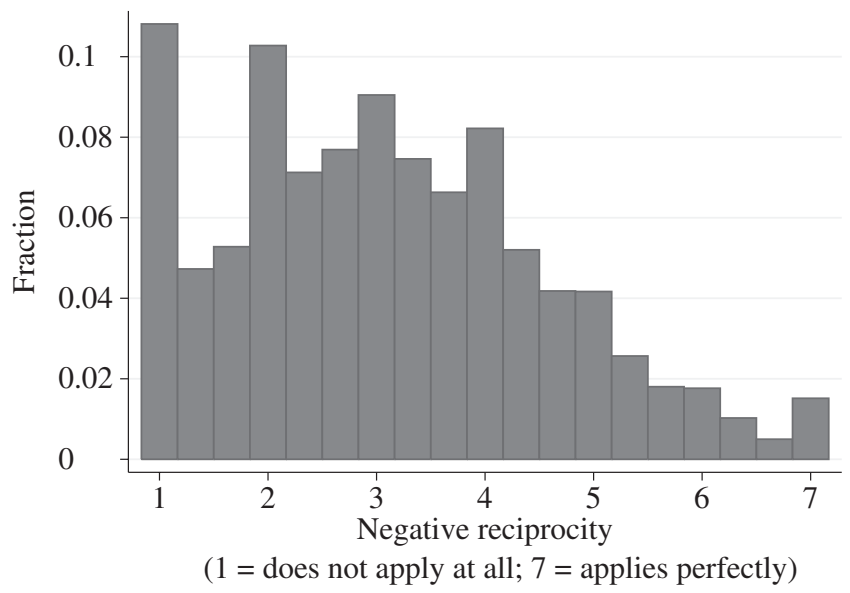

Fig. 2. Distribution of Reciprocity

Notes. The histograms show the distributions of positive and negative reciprocity in the sample of the 20,774 individuals who responded to all six reciprocity measures in the 2005 wave of the SOEP. For each individual, the degree of positive reciprocity is calculated by taking the simple average of responses to the three positive reciprocity measures. Negative reciprocity is based on the average across the three negative reciprocity measures. See notes to Figure 1 for the wording of the reciprocity questions.

${ }^{7}$ Note that the bins do not correspond to integer values because they are constructed using averages of different values on the response scales. Means and standard deviations for positive and negative reciprocity are $5.88(0.91)$ and $3.11(1.46)$, respectively.

(C) The Author(s). Journal compilation (C) Royal Economic Society 2009 
non-trivial fraction report almost complete agreement. In our analysis later on, we will focus on these overall measures of positive and negative reciprocity for each individual.

The correlation between positive and negative reciprocity is only 0.021 , suggesting that these are not part of a single trait. In other words, just because someone is strongly negatively reciprocal does not mean that they are strongly positively reciprocal and vice versa. This finding has implications for modelling reciprocity. As discussed in the Introduction, reciprocity is usually modelled with a single parameter, whereas the weak link between positive and negative reciprocity suggests that a more appropriate specification would include two parameters. It is in fact quite plausible that positive and negative reciprocity could be separate traits, when one considers potential underlying mechanisms. For instance, anger has been shown to be a correlate of strong negative reciprocity (Fehr and Gächter, 2002). Although there is little evidence on the specific emotions associated with positive reciprocity, the emotions associated with positive reciprocity are presumably different than those for negative reciprocity, which is suggestive of a different mechanism.

An alternative way of condensing the information in the reciprocity survey questions is to apply principal components analysis. Principal components analysis on the reciprocity questions reveals that the six survey questions can be represented by two distinct, orthogonal, components with eigenvalues larger than one. Questions about positive reciprocity have high loadings on the first component while questions on negative reciprocity have remarkably low loadings on this component. The reverse is true for the loadings on the second component. ${ }^{8}$ This provides further evidence that positive and negative reciprocity are indeed distinct traits. ${ }^{9}$ The evidence is buttressed by the fact that the correlation between the single component for positive reciprocity that is obtained by a principal component analysis on the positive reciprocity questions only and the analogously obtained single component for negative reciprocity is only 0.014 in the sample of respondents who answered all six reciprocity questions. ${ }^{10}$

In previous research, we have explored the relationship of reciprocity to exogenous individual characteristics, including age, gender and height (Dohmen et al., 2008), as well as the relationship to another social motivation, trust. For example, females have stronger positive reciprocal inclinations and weaker negative reciprocal inclinations than men. Advancing age is associated with a similar pattern of more pronounced positive reciprocity and less pronounced negative reciprocity. Height is also associated with stronger positive reciprocity but is unrelated to negative reciprocity. The fact that negative and positive reciprocity depend on different characteristics in different ways again suggests that these are separate traits.

\footnotetext{
8 The loadings on the first component (positive reciprocity) are respectively $0.5507,0.6218$ and 0.5532 for questions (1), (4) and (6) and $-0.0226,-0.0528$ and -0.0274 for questions (2), (3) and (5). The loadings for the second component are $-0.0407,0.0683,0.0712,0.5849,0.5937$ and 0.5422 for questions (1), (4), (6), (2), (3) and (5) respectively.

9 All qualitative results obtained for the average measures are very similar to results obtained with principal components measures for positive and negative reciprocity.

${ }^{10}$ Correlations between the two principal components that are obtained from an analysis which uses all six questions and the components for positive and negative reciprocity that result from an analysis on the three respective items only corroborate this result: Correlations between components for positive and negative reciprocity are always smaller than 0.07 in absolute terms while correlations between the two different components for positive reciprocity and between those for negative reciprocity exceed 0.997 .
}

(C) The Author(s). Journal compilation (C) Royal Economic Society 2009 


\section{Behavioural Correlates of Reciprocity}

Guided by the experimental literature, in which studies have often investigated how reciprocity affects the employment relationship, we first investigate the correlations between reciprocity and key labour market variables, such as work effort, labour income and employment status. We then turn to another important open question: How successful in life is Homo Reciprocans? We measure success in a variety of ways, including social success measured by number of close friends, and overall satisfaction with life.

\subsection{Reciprocity and Work Effort}

One strand of the experimental literature has documented a willingness of workers to exert high effort levels, even in settings where effort is not enforceable and a purely selfish worker would shirk. The leading explanation for such behaviour is that workers are positively reciprocal and that firms can elicit high effort levels by paying generous wages. In fact, firms are observed to pay greater than market clearing wages in these experiments and average worker effort levels respond to the level of the wage offered in a way consistent with positive reciprocity (Fehr et al., 1993; Fehr and Falk, 1999; Gneezy, 2003). Thus, positive reciprocity can potentially explain why it may be profitable for firms to pay efficiency wages. Likewise, it has been argued that unfair treatment of employees leads to shirking or sabotage activities (Fehr and Falk, 1999; Bewley, 1999). With our measures of reciprocity we provide direct evidence from the field on the worker side of this equation, testing whether reciprocity is associated with effort levels in the workplace.

Our first measure of work effort is a binary variable indicating whether an employee worked overtime hours in the month preceding the interview. Interpreting overtime hours as a measure of additional work effort, we would expect positive coefficients for positive and negative coefficients for negative reciprocity. In Table 1 we report marginal effects estimates of Probit models, in which the dependent variable is equal to 1 if an individual reported working some overtime during the past month and zero otherwise. We report robust standard errors in brackets, adjusted for clustering on household. The results are in line with our predictions, i.e., working overtime depends positively on positive and negatively on negative reciprocity (Column (1)). Given that we have longitudinal data, we can further check whether reciprocity measured in 2005 predicts work effort not only in 2005 but also in later years. This would be suggestive of a causal relationship because working overtime hours in 2006 or 2007 is unlikely to affect measurement of reciprocity in 2005. In Columns (2) and (3) we therefore present results on how the probability of working overtime in 2006 and 2007 is related to reciprocal inclinations in 2005. It turns out that the effect of reciprocity on overtime work in later years is similar to its effect on the current probability of working overtime. For positive reciprocity the effect is actually almost identical. For negative reciprocity, however, it becomes smaller and insignificant in 2007.

So far we have investigated whether reciprocal inclinations predict effort-related behaviour, irrespective of how workers perceive the way they are treated by their

(C) The Author(s). Journal compilation (C) Royal Economic Society 2009 
Table 1

Reciprocity and Work Effort

\begin{tabular}{|c|c|c|c|c|c|}
\hline \multirow[b]{2}{*}{ Dependent Variable: } & \multicolumn{3}{|c|}{$\begin{array}{l}\text { Worked } \\
\text { Overtime Last Month }\end{array}$} & \multicolumn{2}{|c|}{$\begin{array}{c}\text { Worked } \\
\text { Overtime in } 2005\end{array}$} \\
\hline & 2005 & 2006 & 2007 & $\begin{array}{l}\text { Wage } \\
\text { perceived } \\
\text { fair } \\
(4)\end{array}$ & $\begin{array}{c}\text { Wage } \\
\text { perceived } \\
\text { not fair } \\
(5)\end{array}$ \\
\hline \multirow[t]{2}{*}{ Positive reciprocity } & $0.023 * * *$ & $0.025^{* * *}$ & $0.020 * * *$ & $0.038 * * *$ & -0.007 \\
\hline & {$[0.007]$} & {$[0.007]$} & {$[0.007]$} & {$[0.008]$} & {$[0.011]$} \\
\hline \multirow[t]{2}{*}{ Negative reciprocity } & $-0.010 * *$ & $-0.008^{*}$ & 0.002 & $-0.012^{* *}$ & -0.009 \\
\hline & {$[0.004]$} & {$[0.004]$} & {$[0.004]$} & {$[0.005]$} & {$[0.007]$} \\
\hline \multirow[t]{2}{*}{1 if female } & $-0.051 * * *$ & -0.005 & $-0.039 * *$ & $-0.051 * * *$ & $-0.059 * *$ \\
\hline & {$[0.014]$} & {$[0.015]$} & {$[0.015]$} & {$[0.018]$} & {$[0.024]$} \\
\hline \multirow[t]{2}{*}{ Years of education } & $0.006 *$ & 0.004 & $0.007 * *$ & 0.004 & 0.007 \\
\hline & {$[0.003]$} & {$[0.003]$} & {$[0.003]$} & {$[0.004]$} & {$[0.005]$} \\
\hline \multirow[t]{2}{*}{ Full-time work experience (in years) } & $0.008 * * *$ & $0.007 * * *$ & $0.009 * * *$ & $0.006^{* *}$ & $0.011 * * *$ \\
\hline & {$[0.002]$} & {$[0.003]$} & {$[0.003]$} & {$[0.003]$} & {$[0.004]$} \\
\hline \multirow[t]{2}{*}{ Full-time work experience ${ }^{2} / 100$} & $-0.018 * * *$ & $-0.013 * *$ & $-0.017 * * *$ & $-0.015^{* *}$ & $-0.020^{* *}$ \\
\hline & {$[0.005]$} & {$[0.005]$} & {$[0.005]$} & {$[0.006]$} & {$[0.009]$} \\
\hline \multirow[t]{2}{*}{ Part-time work experience (in years) } & $0.011 * * *$ & $0.010 * * *$ & $0.011 * * *$ & $0.011 * *$ & $0.011 *$ \\
\hline & {$[0.004]$} & {$[0.004]$} & {$[0.004]$} & {$[0.005]$} & {$[0.006]$} \\
\hline \multirow[t]{2}{*}{ Part-time work experience ${ }^{2} / 100$} & $-0.034 * *$ & $-0.025^{*}$ & $-0.024 *$ & $-0.040^{* *}$ & -0.023 \\
\hline & {$[0.013]$} & {$[0.014]$} & {$[0.014]$} & {$[0.017]$} & {$[0.023]$} \\
\hline \multirow[t]{2}{*}{ Job tenure (in years) } & $-0.006^{* * *}$ & -0.002 & $-0.006^{* * *}$ & $-0.004^{*}$ & $-0.008 * *$ \\
\hline & {$[0.002]$} & {$[0.002]$} & {$[0.002]$} & {$[0.003]$} & {$[0.003]$} \\
\hline \multirow[t]{2}{*}{ Job tenure ${ }^{2} / 100$} & $0.011^{*}$ & -0.005 & $0.011 * *$ & 0.009 & 0.013 \\
\hline & {$[0.006]$} & {$[0.006]$} & {$[0.005]$} & {$[0.007]$} & {$[0.010]$} \\
\hline \multirow[t]{2}{*}{1 if part-time } & $-0.191 * * *$ & $-0.210^{* * *}$ & $-0.179 * * *$ & $-0.190 * * *$ & $-0.175^{* * *}$ \\
\hline & {$[0.016]$} & {$[0.017]$} & {$[0.018]$} & {$[0.020]$} & {$[0.027]$} \\
\hline \multirow[t]{2}{*}{ Age (in years) } & $-0.005 * * *$ & $-0.005^{* * * *}$ & $-0.007 * * *$ & $-0.004 * *$ & $-0.006^{* *}$ \\
\hline & {$[0.001]$} & [0.002] & [0.002] & {$[0.002]$} & {$[0.003]$} \\
\hline Other Controls & Yes & Yes & Yes & Yes & Yes \\
\hline Observations & 8,462 & 7,611 & 7,301 & 5,626 & 2,815 \\
\hline Pseudo R-squared & 0.07 & 0.08 & 0.08 & 0.08 & 0.07 \\
\hline
\end{tabular}

The dependent variable is a binary variable, taking the value 1 if an individual reports to have worked overtime in the past month. Marginal effects estimates of Probit models (evaluated at the mean of the independent variables) are reported. The measure of positive reciprocity is the individual's average level of agreement to three statements concerning, respectively, willingness to return a favour, to go out of the way to help somebody who was kind and undergo personal costs to help someone who was helpful before. The measure of negative reciprocity reflects average agreement to statements concerning willingness to take revenge for a serious wrong, to retaliate for being put in a difficult position, and to respond to an insult with an insult. Answers are always on a scale from 1 to 7 , where 1 means 'does not apply to me at all' and 7 means 'applies to me perfectly'. The sample is split in Columns (4) and (5) based on the response to the question: 'Is the income that you earn at your current job just, from your point of view?' (translated from German). Regressions in all columns include indicator variables for firm size (5-19, 20-99, 100-199, 200-1999, more than 2000 employees), industrial sector (agriculture, energy, mining, manufacturing, construction, trade, transport, bank and insurance), and occupational status in public and private employment. Detailed results for all control variables are available upon request. Robust standard errors in brackets allow for clustering at the household level; ***, **, * indicate significance at 1\%, 5\%, and $10 \%$ level, respectively.

firms. This makes sense because, ceteris paribus, positively reciprocally motivated workers should be more likely to provide extra effort while negatively reciprocally motivated workers should provide less effort. It would be interesting, however, to additionally know whether perceptions of fairness intensify the effect of reciprocal

(C) The Author(s). Journal compilation (C) Royal Economic Society 2009 
inclination. Put differently, we would expect that working overtime depends not only on reciprocal inclination, but also on whether workers perceive their wages as fair or unfair. The SOEP 2005 wave includes a survey question that asks whether the respondent thinks that his or her wage is fair or not. ${ }^{11}$ This measure is certainly crude in the sense that overall treatment by firms is not only determined by wage payments but also other aspects such as work environment, career chances, fringe benefits etc. Moreover, when answering the question about fair wages, respondents may assess overall fairness of their wage in light of their work effort. Thus finding that reciprocity affects effort choices depending on answers to the fair wage question would be a strong result.

In Columns (4) and (5) of Table 1 we re-estimate the model presented in Column (1) of the table on the sub-samples of employees who perceive their wage in 2005 as being fair (Column (4)) and those who perceive their wage as unfair (Column (5)). Notably, positive reciprocity has a strong positive effect on working overtime among employees who perceive their wage as fair. In other words, positively reciprocal employees are more likely to work overtime if they feel treated in a fair way. For workers who think that their wage is unfair, reciprocal inclinations have a very small and statistically insignificant effect on the probability of working overtime. If we interpret less overtime as a form of shirking or lack of willingness to cooperate in the interest of the firm, the finding that positive reciprocity only matters when the wage is fair clearly makes sense. Less intuitive, however, is the fact that negative reciprocity does not have a significant effect when employees do not think they receive a fair wage.

Another measure for work effort is an individual's frequency of absenteeism. When estimating how the number of days an individual has been absent during the previous year is related to reciprocal inclination, we find evidence that positive reciprocity tends to reduce days of absenteeism while negative reciprocity is associated with more days of absence. These results are significant in models with standard controls such as log gross labour income, years of schooling, a quadratic in part-time and full-time experience, gender, occupational status in public and private sector employment. ${ }^{12}$ Positively reciprocal inclinations are associated with taking significantly less sick days, while the opposite holds for negatively reciprocal inclinations. These results hold for 2005 and 2006. ${ }^{13}$ However, the results become insignificant when adding controls for occupation, firm size and industry. Overall, our findings on work effort support the hypothesis that effort levels in the workplace are increasing in positive reciprocity. There is also evidence that workers' negatively reciprocal inclinations find expression through reduced willingness to work overtime, and greater absenteeism.

11 The wording of the question translated from German is 'Is the income that you earn at your current job just, from your point of view?'

${ }^{12}$ In order to account for a substantial number of observations with no days absent, coefficients are estimated using Tobit regressions. In these regressions we exclude observations on those who had a long-term illness, defined as an illness lasting longer than six weeks.

13 Information on absenteeism is based on retrospective information. In each wave, respondents are asked for the number of days they were absent at work due to sickness in the previous year, including days of absence without a medical certificate.

(C) The Author(s). Journal compilation (C) Royal Economic Society 2009 


\subsection{Reciprocity, Wages and Unemployment Probability}

We now turn to the hypothesised link between reciprocal inclinations of workers and how workers are treated by employers. Recall that based on positive reciprocity or giftexchange in the labour market, efficiency wage theory predicts higher wages to reciprocating workers than to non-reciprocating workers (Akerlof, 1982). This hypothesis has been supported in numerous laboratory experiments. Gächter and Falk (2002), for example, study bilateral labour relations and show that employers gradually increase wage payments as a response to increased effort levels. As a result workers who are more reciprocal receive higher wages. In light of the experimental and theoretical work we hypothesise that workers who show a tendency to reward high wages with high effort, i.e., who are positively reciprocal, also receive higher wages. Table 2 presents Mincer-type earnings regressions where the dependent variable is shown as different measures of the logarithm of an individual's gross labour income. In particular, the dependent variable in Columns (1) to (3) is a measure of log gross monthly labour earnings in the years 2005 to 2007, while the dependent variable in Columns (4) and (5) measures log gross annual labour earnings in 2005 and 2006, respectively. ${ }^{14}$ The regressions are based on the subsample of employees. ${ }^{15}$ Besides reciprocal inclinations, the controls include information on gender, years of education, full-time and part-time experience, tenure, part time, contractual weekly hours, firm size, industry and occupation. ${ }^{16}$ The results for labour earnings in 2005 (see Columns (1) and (4)) are consistent with the typical findings for this type of regression, namely lower labour incomes for women, an increasing and concave experience effect, and significant education effects. Most interestingly, however, individuals exhibiting positive reciprocity tend to earn significantly higher labour incomes, regardless of the income measure (monthly or annual). This effect is also economically significant. Moving one point on the reciprocity scale, and assuming a linear relationship, implies an effect on wages which is about $10 \%$ of the size of the gender effect. The results are consistent with the directed hypothesis from the experimental literature, that positively reciprocal types should be observed to receive higher wages. To provide further evidence in favour of a causal interpretation we check whether reciprocity measured in 2005 predicts wages in later years in addition to predicting the wage in 2005. In Columns (2), (3) and (5) we regress gross monthly labour income in 2006 and 2007 and annual labour income in 2006, respectively on reciprocal inclination in 2005. It turns out that the effect of positive reciprocity on future wages is similar to its effect on current wages, both in terms of size and significance.

Table 2 also shows that negative reciprocity has no significant effect on labour income. This makes sense, given that employers cannot expect negatively reciprocal types to reciprocate positively for generous wages, and given that paying low wages to negatively reciprocal types may be a very bad idea due to potential sanctions.

\footnotetext{
14 Annual labour earnings are taken from the equivalent files of the SOEP, which contain income measures that are constructed based on retrospective calendar information on monthly labour market status and monthly earnings, income and benefits. Annual income measures in a particular wave hence refer to income in the previous year. Since the data for the 2008 wave was not available at the time of writing this article, we lack a measure of annual earnings for 2007.

${ }^{15}$ We exclude self-employed, retired, unemployed, members of the armed forces, non-participants and persons still in education.

${ }^{16}$ See also the notes of Table 2 for more details.
}

(C) The Author(s). Journal compilation (C) Royal Economic Society 2009 
Table 2

Reciprocity and Labour Income

\begin{tabular}{|c|c|c|c|c|c|}
\hline \multirow[b]{2}{*}{ Dependent variable: } & \multicolumn{3}{|c|}{$\begin{array}{c}\text { Log Gross } \\
\text { Monthly Labour Income }\end{array}$} & \multicolumn{2}{|c|}{$\begin{array}{l}\text { Log Gross } \\
\text { Annual Labour Income }\end{array}$} \\
\hline & $\begin{array}{c}2005 \\
(1)\end{array}$ & $\begin{array}{c}2006 \\
(2)\end{array}$ & $\begin{array}{c}2007 \\
(3)\end{array}$ & $\begin{array}{c}2005 \\
(4)\end{array}$ & $\begin{array}{c}2006 \\
(5)\end{array}$ \\
\hline \multirow[t]{2}{*}{ Positive reciprocity } & $0.012 * *$ & $0.019 * * *$ & $0.009 *$ & $0.018 * * *$ & $0.016 * * *$ \\
\hline & {$[0.005]$} & {$[0.006]$} & {$[0.005]$} & {$[0.006]$} & {$[0.006]$} \\
\hline \multirow[t]{2}{*}{ Negative reciprocity } & 0.000 & -0.004 & 0.003 & -0.003 & 0.001 \\
\hline & {$[0.003]$} & {$[0.003]$} & {$[0.003]$} & {$[0.004]$} & {$[0.004]$} \\
\hline \multirow[t]{2}{*}{1 if female } & $-0.154 * * *$ & $-0.170 * * *$ & $-0.166^{* * *}$ & $-0.174 * * *$ & $-0.176^{* * *}$ \\
\hline & {$[0.012]$} & {$[0.012]$} & {$[0.013]$} & {$[0.013]$} & {$[0.014]$} \\
\hline \multirow[t]{2}{*}{ Years of education } & $0.030 * * *$ & $0.033 * * *$ & $0.030 * * *$ & $0.035 * * *$ & $0.033 * * *$ \\
\hline & {$[0.002]$} & {$[0.003]$} & {$[0.003]$} & {$[0.003]$} & {$[0.003]$} \\
\hline \multirow[t]{2}{*}{ Full-time work experience (in years) } & $0.021 * * *$ & $0.021 * * *$ & $0.022 * * *$ & $0.028 * * *$ & $0.030 * * *$ \\
\hline & {$[0.002]$} & {$[0.002]$} & {$[0.002]$} & {$[0.002]$} & {$[0.002]$} \\
\hline \multirow[t]{2}{*}{ Full-time work experience $^{2} / 100$} & $-0.043^{* * *}$ & $-0.041 * * *$ & $-0.043^{* * *}$ & $-0.054 * * *$ & $-0.057 * * *$ \\
\hline & {$[0.004]$} & {$[0.004]$} & {$[0.004]$} & {$[0.005]$} & {$[0.005]$} \\
\hline \multirow{2}{*}{ Part-time work experience (in years) } & -0.004 & -0.001 & $-0.007 * *$ & $0.006 * *$ & $0.008 * *$ \\
\hline & {$[0.003]$} & {$[0.003]$} & {$[0.003]$} & {$[0.003]$} & {$[0.003]$} \\
\hline \multirow[t]{2}{*}{ Part-time work experience ${ }^{2} / 100$} & $0.017 *$ & 0.000 & 0.017 & -0.018 & -0.015 \\
\hline & {$[0.010]$} & {$[0.011]$} & {$[0.011]$} & {$[0.012]$} & {$[0.012]$} \\
\hline \multirow[t]{2}{*}{ Job tenure (in years) } & $0.015^{* * *}$ & $0.013 * * *$ & $0.013^{* * *}$ & $0.017 * * *$ & $0.022 * * *$ \\
\hline & {$[0.002]$} & {$[0.002]$} & {$[0.002]$} & {$[0.002]$} & {$[0.002]$} \\
\hline \multirow[t]{2}{*}{ Job tenure ${ }^{2} / 100$} & $-0.022 * * *$ & $-0.019 * * *$ & $-0.019 * * *$ & $-0.027 * * *$ & $-0.038 * * *$ \\
\hline & {$[0.004]$} & {$[0.005]$} & {$[0.005]$} & {$[0.005]$} & {$[0.005]$} \\
\hline \multirow[t]{2}{*}{1 if part-time } & $-0.065^{* * *}$ & $-0.137 * * *$ & $-0.198 * * *$ & $-0.198 * * *$ & $-0.340 * * *$ \\
\hline & {$[0.016]$} & {$[0.020]$} & {$[0.018]$} & {$[0.024]$} & {$[0.024]$} \\
\hline \multirow[t]{2}{*}{ Contractual weekly hours } & $0.025^{* * *}$ & $0.017 * * *$ & $0.011 * * *$ & $0.016 * * *$ & $0.010 * * *$ \\
\hline & {$[0.001]$} & {$[0.001]$} & {$[0.001]$} & {$[0.001]$} & {$[0.001]$} \\
\hline \multirow[t]{2}{*}{ Constant } & $5.946 * * *$ & $6.179 * * *$ & $6.482 * * *$ & $8.588 * * *$ & $8.822 * * *$ \\
\hline & {$[0.071]$} & {$[0.075]$} & {$[0.071]$} & {$[0.081]$} & {$[0.080]$} \\
\hline Other Controls & Yes & Yes & Yes & Yes & Yes \\
\hline Observations & 7,928 & 6,866 & 6,328 & 6,867 & 6,330 \\
\hline R-squared & 0.64 & 0.63 & 0.62 & 0.62 & 0.62 \\
\hline
\end{tabular}

The dependent variable in Columns (1) to (3) is log gross monthly labour earnings (taken from the generated files vpgen, wpgen and xpgen of the SOEP). The dependent variable in Columns (4) and (5) is log annual individual labour earnings (taken from the equivalent files of the SOEP). The sample is restricted to the employed; farmers, self-employed, those in compulsory military or community service are excluded. The measure of positive reciprocity is the individual's average level of agreement to three statements concerning, respectively, willingness to return a favour, to go out of the way to help somebody who was kind, and undergo personal costs to help someone who was helpful before. The measure of negative reciprocity reflects average agreement to statements concerning willingness to take revenge for a serious wrong, to retaliate for being put in a difficult position and to respond to an insult with an insult. Answers are always on a scale from 1 to 7 , where 1 means 'does not apply to me at all' and 7 means 'applies to me perfectly'. Regressions in all columns include indicator variables for firm size (5-19, 20-99, 100-199, 200-1999, more than 2000 employees), industrial sector (agriculture energy, mining, manufacturing, construction, trade, transport, bank and insurance), and occupational status in public and private employment. Detailed results for all control variables are available upon request. Robust standard errors in brackets allow for clustering at the household level; $* * *, * *, *$ indicate significance at $1 \%, 5 \%$, and $10 \%$ level, respectively.

We next consider the relationship between reciprocity and the likelihood of being unemployed. Experimental and field evidence suggests that positive reciprocity may help to sustain successful employment relationships and that negative reciprocity may be associated with relationship dissolution and unemployment. For example, Brown et al. (2004) conduct an experiment where long-term relationships can emerge

(C) The Author(s). Journal compilation (C) Royal Economic Society 2009 
endogenously between a firm and a worker, and find that positive reciprocity is important for establishing successful long-term relationships. ${ }^{17}$ To the extent that positive reciprocity also helps to sustain successful employment relationships outside the laboratory, one would then expect that positively reciprocal individuals are less likely to be unemployed.

On the other hand, there is reason to believe that negatively reciprocal types may be more likely to be unemployed. Experiments show that people are willing to punish those who treat them unfairly, even if this is personally costly (Fehr and Gächter, 2002; Quervaine et al., 2004). For this reason, negatively reciprocal types might be more likely to quit their job following unfair treatment by an employer than positively reciprocal types. Alternatively, negatively reciprocal types might decide to punish the employer by shirking on the job (see also our findings on absenteeism, discussed above). In this case, the employer has an incentive to pre-empt such retaliation by dismissing the worker. One dramatic example of the damage caused by disgruntled workers is provided by Krueger and Mas (2004). Related evidence shows that managers of firms are reluctant to cut nominal wages, for fear that this will trigger negative reciprocity and retaliation from workers (Bewley, 1999). Thus, it is quite plausible in the case of conflict that dismissing negatively reciprocal workers seems optimal, as opposed to cutting wages.

In order to test these hypotheses regarding the relationship between unemployment and reciprocity, Table 3 presents results for an indicator for employment status, equal to 1 if an individual is currently registered as unemployed, and zero otherwise, as the dependent variable. Controls include years of education, gender, age, region of residence and an indicator for German citizenship. The Table shows that positively reciprocal individuals are in fact significantly less likely to be unemployed. On the other hand, negatively reciprocal individuals are significantly more likely to be unemployed. These findings are consistent with the hypothesis that individuals' reciprocal inclinations affect their labour market experience, in terms of ability or willingness to sustain long-term employment relationships. They also suggest that employers choose to respond to negative reciprocity on the margin of employment or unemployment, rather than the margin of adjusting wages (Bewley, 1999). Again, in terms of magnitude, reciprocity is as important as other key economic variables. In Column (2) we include region dummies at the state level (Bundesland) as a further control since unemployment in Germany varies substantially across different regions. All coefficients remain basically unchanged.

Again it would be reassuring of a causal interpretation if reciprocal inclinations would not only predict current but also future unemployment. This is why we regress unemployment in 2006 and 2007 on our 2005 measures of reciprocity in Columns (3) to (6). In Columns (4) and (6) we also include region dummies. In comparison to current unemployment in 2005, the effects become somewhat smaller for 2006 and 2007. This holds in particular for positive reciprocity. However, all effects remain

\footnotetext{
17 In the experiment, effort is not enforceable, so short-run self-interest dictates that workers shirk and firms pay minimal wages. Relationships that ultimately last a long time, however, start with higher wages and higher effort levels than shorter relationships. Workers earn more in long-term relationships than in shortterm relationships but also work harder, because they reciprocate the generous wages.
} 
Table 3

Reciprocity and Unemployment

\begin{tabular}{|c|c|c|c|c|c|c|}
\hline \multirow[b]{2}{*}{ Dependent variable: } & \multicolumn{2}{|c|}{$\begin{array}{l}1 \text { if unemployed } \\
\text { in } 2005\end{array}$} & \multicolumn{2}{|c|}{$\begin{array}{l}1 \text { if unemployed } \\
\text { in } 2006\end{array}$} & \multicolumn{2}{|c|}{$\begin{array}{l}1 \text { if unemployed } \\
\text { in } 2007\end{array}$} \\
\hline & (1) & (2) & (3) & (4) & (5) & (6) \\
\hline \multirow[t]{2}{*}{ Positive reciprocity } & $-0.010 * * *$ & $-0.010 * * *$ & $-0.006^{* *}$ & $-0.005^{*}$ & $-0.005^{*}$ & $-0.005^{*}$ \\
\hline & {$[0.003]$} & {$[0.003]$} & {$[0.003]$} & {$[0.003]$} & {$[0.003]$} & {$[0.003]$} \\
\hline \multirow[t]{2}{*}{ Negative reciprocity } & $0.006 * * *$ & $0.006^{* * * *}$ & $0.004 * *$ & $0.004 * *$ & $0.004 * *$ & $0.003 * *$ \\
\hline & {$[0.002]$} & {$[0.002]$} & {$[0.002]$} & {$[0.002]$} & {$[0.002]$} & {$[0.002]$} \\
\hline \multirow[t]{2}{*}{ Years of education } & 0.001 & 0.001 & 0.004 & 0.004 & $0.019 * * *$ & $0.019 * * *$ \\
\hline & {$[0.005]$} & {$[0.005]$} & {$[0.005]$} & {$[0.005]$} & {$[0.005]$} & {$[0.004]$} \\
\hline \multirow[t]{2}{*}{1 if female } & $-0.018 * * *$ & $-0.018^{* * * *}$ & $-0.018 * * *$ & $-0.018 * * *$ & $-0.014^{* * * *}$ & $-0.014^{* * *}$ \\
\hline & {$[0.001]$} & {$[0.001]$} & {$[0.001]$} & {$[0.001]$} & {$[0.001]$} & {$[0.001]$} \\
\hline \multirow[t]{2}{*}{ Age (in years) } & $0.001 * * *$ & $0.001 * * *$ & $0.002 * * *$ & $0.002 * * *$ & $0.002 * * *$ & $0.002^{* * * *}$ \\
\hline & {$[0.000]$} & {$[0.000]$} & {$[0.000]$} & {$[0.000]$} & {$[0.000]$} & {$[0.000]$} \\
\hline \multirow[t]{2}{*}{ Lived in GDR in 1989} & $0.083 * * *$ & 0.011 & $0.085^{* * *}$ & $0.032 * * *$ & $0.073 * * *$ & $0.019 *$ \\
\hline & {$[0.008]$} & {$[0.011]$} & {$[0.009]$} & {$[0.012]$} & {$[0.009]$} & {$[0.011]$} \\
\hline \multirow[t]{2}{*}{ Lived abroad in 1989} & $0.063 * * *$ & $0.058 * * *$ & $0.055^{* * *}$ & $0.047 * * *$ & $0.080 * * *$ & $0.073^{*} * *$ \\
\hline & {$[0.017]$} & {$[0.017]$} & {$[0.018]$} & {$[0.017]$} & {$[0.020]$} & {$[0.019]$} \\
\hline \multirow{2}{*}{$\begin{array}{l}\text { Residence in } 1989 \\
\text { missing }\end{array}$} & 0.099 & 0.055 & 0.039 & 0.007 & 0.143 & 0.094 \\
\hline & {$[0.071]$} & {$[0.062]$} & {$[0.056]$} & {$[0.045]$} & {$[0.093]$} & {$[0.081]$} \\
\hline \multirow[t]{2}{*}{ German nationality } & $-0.030 * *$ & $-0.036^{* *}$ & $-0.043^{* * * *}$ & $-0.049 * * *$ & -0.005 & -0.008 \\
\hline & {$[0.013]$} & {$[0.014]$} & {$[0.015]$} & {$[0.016]$} & [0.012] & {$[0.013]$} \\
\hline Other Controls & Yes & Yes & Yes & Yes & Yes & Yes \\
\hline $\begin{array}{l}\text { Region (Bundesland) } \\
\text { dummies }\end{array}$ & No & Yes & No & Yes & No & Yes \\
\hline Observations & 12,640 & 12,640 & 11,460 & 11,460 & 10,740 & 10,740 \\
\hline Pseudo R-squared & 0.11 & 0.12 & 0.11 & 0.11 & 0.10 & 0.12 \\
\hline
\end{tabular}

The dependent variable takes the value 1 if the respondent is unemployed at the survey date in 2005 (Columns (1) and (2)), 2006 (Columns (3) and (4)), or 2007 (Columns (5) and (6)). Estimates are Probit marginal effects estimates. The measure of positive reciprocity is the individual's average level of agreement to three statements concerning, respectively, willingness to return a favour, to go out of the way to help somebody who was kind and undergo personal costs to help someone who was helpful before. The measure of negative reciprocity reflects average agreement to statements concerning willingness to take revenge for a serious wrong, to retaliate for being put in a difficult position and to respond to an insult with an insult. Answers are always on a scale from 1 to 7 , where 1 means 'does not apply to me at all' and 7 means 'applies to me perfectly'. Additional other controls are marital status, number of children in the household and religious background. All regressions include indicator variables for marital status (married, widowed, divorced), for the number of children in the household ( 1 child, 2 children, 3 children, 4 or more children) and categorical variables for religion (catholic, other Christian, other religion, no confession, religion missing). We use information on religion from the 2003 wave in Columns (1)-(4). Religion information from the 2007 survey is used in Columns (5) and (6). An additional religion category (islamic), that was previously subsumed in the category 'other religion' was defined in 2007. Regressions in Columns (2), (4) and (6) include dummy variables for the state (Bundesland) of residence (Saarland and Rhineland-Palatinate are subsumed in one category). Robust standard errors in brackets allow for clustering at the household level; ***, **, * indicate significance at $1 \%, 5 \%$, and $10 \%$ level, respectively.

significant at least at the $5 \%$ level for both positive and negative reciprocity, suggesting a causal link from reciprocal inclination to unemployment.

\subsection{Success of Homo Reciprocans}

In this Section we investigate the success of homo reciprocans, by studying how reciprocal inclinations affect various success measures. This investigation is in line with a growing literature that focuses on the importance of personality, attitudes, or

(C) The Author(s). Journal compilation (C) Royal Economic Society 2009 
non-cognitive skills for determining the economic success of individuals also in an evolutionary context (Bowles and Gintis, 2002; Heckman and Rubinstein, 2001; Heckman et al., 2006; Osborne, 2005). It is also related to recent work investigating whether people who are more generous are more successful in the sense of having greater life satisfaction (see Konow and Earley, 2008; Becchetti and Degli, 2007).

There are various reasons why reciprocal behaviour could lead to better or worse outcomes for an individual. On the one hand, reciprocity is costly, because individuals spend resources to reciprocate favours or insults, in circumstances where material selfinterest would dictate no response. On the other hand there are potential long-term benefits that could outweigh these costs, for example, heightened ability to sustain relationships, or ability to credibly threaten punishment of unfair behaviour. It is therefore interesting to investigate how Homo Reciprocans fares in life, compared to individuals who are only weakly reciprocal or not reciprocal at all. ${ }^{18}$

Our results on labour income and unemployment already indicate that reciprocal inclinations are associated with economic success. There is no obvious reason to confine success only to the economic domain, however. While there are various reasons why reciprocal behaviour could lead to better or worse outcomes for an individual, it is clear that reciprocity works through social interactions. It is therefore informative to also look at other social outcome variables when gauging the success of homo reciprocans. We use two such outcomes as measures of success. The first is the number of close friends. This is interesting both because it is an important determinant of individual well-being and social success, and because it indicates a type of social intelligence, or ability to sustain long-term relationships. The second is subjective well-being or life satisfaction.

Friendship is known to be associated with various types of positive outcomes for an individual, including, for example, better health. Social networks have also been linked to success in finding employment and receiving informal credit. To the extent that reciprocity sustains or damages friendships, therefore, it has the potential to affect individual well-being. Column (1) of Table 4 presents regressions where the dependent variable is the number of 'close friends' that an individual reports having. ${ }^{19}$ Independent variables include the degree of positive and negative reciprocity for the individual, and the usual exogenous factors as well as additional controls. The coefficient estimates show that reciprocity does have a strong effect on friendship relations. Positive reciprocity is associated with a greater number of close friends, and negative reciprocity is associated with having fewer close friends. Notably, the impact of reciprocity on the ability to sustain friendship relationships is consistent with our previous findings on how reciprocity affects the probability of being in another type of relationship, i.e., being employed. Column (2) adds trust as an additional control to rule out any confounds working through the correlation between reciprocity and trust. While trust has a significant positive effect, the coefficient estimates of interest, those of positive and negative reciprocity, are virtually unchanged: positively reciprocal tendencies facilitate

\footnotetext{
18 This is also important from an evolutionary game theoretic perspective that is concerned with explaining why different types (such as selfish or reciprocal) can coexist (Bowles and Gintis, 2004).

19 The question about close friends was asked in the 2003 wave, so the regression includes only those individuals who were also in the survey in 2003. Results are qualitatively similar if we use a Tobit model instead of OLS.
}

(C) The Author(s). Journal compilation (C) Royal Economic Society 2009 
Table 4

Overall Success of Homo Reciprocans

\begin{tabular}{|c|c|c|c|c|c|}
\hline \multirow[b]{2}{*}{ Dependent Variable: } & \multicolumn{2}{|c|}{$\begin{array}{l}\text { Number } \\
\text { of Friends }\end{array}$} & \multicolumn{3}{|c|}{$\begin{array}{l}\text { Overall Life } \\
\text { Satisfaction }\end{array}$} \\
\hline & (1) & (2) & $\begin{array}{l}2005 \\
(3)\end{array}$ & $\begin{array}{c}2006 \\
(4)\end{array}$ & $\begin{array}{c}2007 \\
(5)\end{array}$ \\
\hline \multirow[t]{2}{*}{ Positive reciprocity } & $0.218 * * *$ & $0.214 * * *$ & $0.170 * * *$ & $0.123 * * *$ & $0.095 * * *$ \\
\hline & {$[0.038]$} & {$[0.038]$} & {$[0.016]$} & {$[0.016]$} & {$[0.016]$} \\
\hline \multirow[t]{2}{*}{ Negative reciprocity } & $-0.057 * *$ & $-0.064 * *$ & $-0.091 * * *$ & $-0.074^{* * *}$ & $-0.056 * * *$ \\
\hline & {$[0.027]$} & {$[0.027]$} & {$[0.010]$} & {$[0.010]$} & {$[0.010]$} \\
\hline \multirow[t]{2}{*}{ Years of education } & $0.066^{* * *}$ & $0.068^{* * *}$ & 0.006 & 0.009 & $0.014^{* *}$ \\
\hline & {$[0.018]$} & {$[0.018]$} & {$[0.006]$} & {$[0.006]$} & {$[0.006]$} \\
\hline \multirow[t]{2}{*}{1 if female } & -0.092 & $-0.105^{*}$ & $0.055^{* *}$ & $0.050 * *$ & $0.049 *$ \\
\hline & {$[0.062]$} & {$[0.062]$} & {$[0.025]$} & {$[0.026]$} & {$[0.026]$} \\
\hline \multirow[t]{2}{*}{ Age (in years) } & $0.012 * * *$ & 0.007 & $0.008^{* * *}$ & $0.008 * * *$ & 0.008 \\
\hline & {$[0.005]$} & {$[0.005]$} & {$[0.002]$} & {$[0.002]$} & {$[0.000]$} \\
\hline \multirow[t]{2}{*}{ Lived in GDR in 1989} & 0.078 & 0.056 & $-0.448 * * *$ & $-0.468 * * *$ & $-0.427 * * *$ \\
\hline & {$[0.109]$} & {$[0.108]$} & {$[0.040]$} & {$[0.040]$} & {$[0.040]$} \\
\hline \multirow[t]{2}{*}{ Lived abroad in 1989} & $-0.463^{* *}$ & $-0.438^{*}$ & -0.004 & 0.050 & $0.172 * *$ \\
\hline & {$[0.233]$} & {$[0.230]$} & {$[0.080]$} & {$[0.081]$} & {$[0.087]$} \\
\hline \multirow{2}{*}{$\begin{array}{l}\text { Residence in } 1989 \\
\text { missing }\end{array}$} & $-0.959 * * *$ & $-1.006^{* * *}$ & 0.592 & -0.115 & 0.643 \\
\hline & {$[0.359]$} & {$[0.277]$} & {$[0.963]$} & {$[0.672]$} & {$[1.335]$} \\
\hline \multirow[t]{2}{*}{ Subjective health } & $-0.283^{* * *}$ & $-0.181 * * *$ & $-0.818^{* * *}$ & $-0.832^{* * *}$ & $-0.876 * * *$ \\
\hline & {$[0.041]$} & {$[0.041]$} & {$[0.017]$} & {$[0.018]$} & {$[0.018]$} \\
\hline \multirow{4}{*}{$\begin{array}{l}\text { Log net annual } \\
\text { household income } \\
1 \text { if unemployed }\end{array}$} & $0.215 * * *$ & $0.291 * * *$ & $0.298 * * *$ & $0.357 * * *$ & $0.286 * * *$ \\
\hline & {$[0.068]$} & {$[0.068]$} & {$[0.026]$} & {$[0.026]$} & {$[0.028]$} \\
\hline & -0.062 & -0.027 & $-1.001 * * *$ & $-0.856^{* * *}$ & $-0.806^{* * *}$ \\
\hline & {$[0.173]$} & {$[0.174]$} & {$[0.075]$} & {$[0.076]$} & {$[0.084]$} \\
\hline \multirow[t]{2}{*}{1 if non-participating } & 0.123 & 0.158 & 0.008 & $0.680 * * *$ & -0.014 \\
\hline & {$[0.155]$} & {$[0.152]$} & {$[0.060]$} & {$[0.231]$} & {$[0.065]$} \\
\hline \multirow[t]{2}{*}{1 if retired } & -0.057 & 0.144 & $0.229 * * *$ & $0.187 * * *$ & $0.173^{* * *}$ \\
\hline & {$[0.168]$} & {$[0.170]$} & {$[0.058]$} & {$[0.061]$} & {$[0.060]$} \\
\hline \multirow[t]{2}{*}{ Trust (standardised) } & $0.468 * * *$ & $0.488 * * *$ & $0.187 * * *$ & $0.189 * * *$ & $0.150 * * *$ \\
\hline & {$[0.041]$} & {$[0.041]$} & {$[0.014]$} & {$[0.014]$} & {$[0.015]$} \\
\hline \multirow[t]{2}{*}{ Constant } & $1.463^{*}$ & 2.406 & $4.481 * * *$ & $3.313 * * *$ & $5.326 * * *$ \\
\hline & {$[0.805]$} & [2.582] & {$[0.470]$} & {$[0.663]$} & {$[0.378]$} \\
\hline Other Controls & Yes & Yes & Yes & Yes & Yes \\
\hline Observations & 15,747 & 15,972 & 16,402 & 15,069 & 13,904 \\
\hline R-squared & 0.04 & 0.04 & & & \\
\hline Pseudo-Log-Likelihood & & & $-29,958$ & $-27,191$ & $-24,907$ \\
\hline
\end{tabular}

OLS coefficient estimates in Columns (1) and (2). The dependent variable in Columns (1) and (2) is the number of close friends and is constructed based on the answer to a question in the 2003 wave. Time-variant explanatory variables are fixed at the values for 2003 in Column (1) and 2005 in Column (2). The dependent variable in Columns (3) to (5) is the answer to a question on overall life satisfaction on a scale from 0 to 10 , where 0 means 'completely dissatisfied' and 10 means 'completely satisfied'. Because the dependent variable is elicited in intervals, coefficients are based on interval regression, which corrects for left and right censoring of the dependent variable. The measure of positive reciprocity is the individual's average level of agreement to three statements concerning, respectively, willingness to return a favour, to go out of the way to help somebody who was kind, and undergo personal costs to help someone who was helpful before. The measure of negative reciprocity reflects average agreement to statements concerning willingness to take revenge for a serious wrong, to retaliate for being put in a difficult position and to respond to an insult with an insult. Answers are always on a scale from 1 to 7 , where 1 means 'does not apply at all' and 7 means 'totally applies'. The measure for annual income is taken form the equivalent files of the SOEP and captures all income sources of the household in the previous year (including for example, earnings, non-labour income, social support, unemployment insurance, retirement and pension benefits and any other benefits). The other controls include parental education background (indicator variables for completion of the Abitur by mothers and fathers), marital status, indicator variables for the number of children under the age of 19 in the household, indicator variables for enrollment in school and different vocational education programmes, categorical variables for labour market status and occupational status in private and public sector employment, categorical variables for religious background, social and national background, and month of interview. The measure of trust is based on standardised answers to a general trust question asked in the 2003 wave of the SOEP. Detailed results are available upon request. Robust standard errors in brackets allow for cluster at the household level; ***, **, * indicate significance at $1 \%$, $5 \%$, and $10 \%$ level, respectively.

(C) The Author(s). Journal compilation (C) Royal Economic Society 2009 
having more friends, while the opposite is true for negatively reciprocal inclinations. Thus, it appears to be a robust finding that positive reciprocity and negative reciprocity are helpful and harmful for sustaining long-term relationships, respectively, whether in the domain of employment relationships or when considering social relationships such as friendships.

Perhaps the ultimate measure of success for an individual is how satisfied they are, subjectively, with their own life. To investigate how reciprocal inclinations affect life satisfaction, we use a standard measure asking the individual to rate satisfaction with their life on an 11-point scale, where 0 indicates 'completely dissatisfied' and 10 indicates 'completely satisfied'. Columns (3) to (5) in Table 4 report regressions where life satisfaction is the dependent variable. In Column (3) we use data from 2005, while Columns (4) and (5) use data from 2006 and 2007, respectively. To account for the fact that the dependent variable is measured in intervals, and thus is left and right censored, coefficients are based on interval regression. The results are striking: a high level of positive reciprocal attitudes is associated with greater life satisfaction, while negative reciprocity tends to make individuals less satisfied with their life. This holds regardless of whether we regress current or future levels of life satisfaction (in 2006 and 2007) on reciprocal inclination measured in 2005. Notably, the additional controls all have the effects typically found in life-satisfaction regressions (van Praag and Ferrer-i-Carbonell, 2004). For example, women and older individuals tend to be more satisfied with their lives, marriage has a strong positive effect and divorce significantly decreases life satisfaction. As is typically the case, unemployment and a bad health status have the largest negative effects on life satisfaction of all controls. Higher education, reflected by having passed the (Abitur) exam, makes individuals more satisfied, and income as well as higher levels of trust have a significant positive effect on subjective well-being. ${ }^{20}$ Also, note that the effects of reciprocity on happiness are quite large. They are in the same order of magnitude as the gender effect or being married.

\section{Concluding Remarks}

This article provides evidence that positive and negative reciprocity are associated with economic outcomes in an asymmetric way. Being positively reciprocal predicts higher work effort, lower unemployment and also higher subjective well-being. Negative reciprocity on the other hand is associated with a higher frequency of unemployment and lower levels of happiness. This result is important because most people in the population have reciprocal inclinations and differ in the degree to which they are positively or negatively reciprocal.

The fact that reciprocal inclinations are related to subjective well-being is consistent with recent models of pro-social behaviour based on identity or self-image. In the model of Benabou and Tirole (2006), for example, individuals gain utility from conforming to social expectations, or morals, regarding pro-social behaviour. Acting in accordance with these expectations signals to the individual that they are a good person

\footnotetext{
20 The income variable is in logarithms and comprises all sources of income, including non-labour income and social support. The results are similar when using a linear specification, or restricting attention to labour income only.

(C) The Author(s). Journal compilation (c) Royal Economic Society 2009
} 
and this feeling of positive self-image yields higher utility. To the extent that there is a social expectation that people should reciprocate kindness, positive reciprocity has a positive impact on happiness. This makes people more willing to invest in positive selfimage by engaging in positive reciprocity. To the extent that negative reciprocity, or revenge, is less socially acceptable, because of conflict with moral rules such as 'turning the other cheek', the long-run effect of negative reciprocity is a lower self-image and reduced life satisfaction.

Our findings add to the understanding of reciprocity, which is probably the most important type of social preferences. The prevalence of reciprocity calls for an intensified investigation of the economic consequences of reciprocity, e.g., for labour relations and social policy issues (Bowles and Gintis, 1998). For example, policies that reward people independent of their contribution to society will most likely be less supported by the public than policies that account for reciprocal considerations. As an example, take the debate about workfare vs. welfare. Unlike regular public assistance, workfare requires recipients to spend time on mandatory activities such as community work, making receipt of benefits conditional on contribution to society. In the presence of reciprocally motivated taxpayers, who reward in-kind, we would expect that support in favour of workfare programmes where recipients 'do their part' is more pronounced than often assumed.

In the labour market the existence of reciprocity can also have important implications for the effects of labour market institutions. For example, minimum wages can play a role as reference wages, affecting the notion of what constitutes a fair wage. In other words, a given wage is considered less fair the higher the minimum wage. Therefore, changing the minimum wage can systematically affect efficiency via effort choices of reciprocally motivated workers (Card and Krueger, 1995; Falk et al., 2006). Reciprocity can also give rise to efficiency wages, implying that labour markets are endogenously rigid, i.e., wages do not necessarily converge to market clearing levels even in the absence of labour market institutions.

The existence of reciprocity also offers new channels for policy interventions, e.g., in the context of tax evasion. The typical policy recommendation that is based on the assumption of purely selfish individuals would entail that tax evasion can be reduced by either increasing fines or detection probabilities. Reciprocity offers an additional perspective. If taxpayers are reciprocal, i.e., conditionally cooperative, they are more willing to pay taxes if the tax system is considered as fair and if other taxpayers are expected to pay their taxes as well. The latter argument suggests the existence of two types of equilibria, a good one where people pay taxes and expect others to pay taxes and a bad one where people do not pay taxes in the expectation that others do not pay their taxes either. Tax policy could try to reach good equilibria with the help of expectation management and improving the perceived fairness and transparency of the tax system.

Maastricht University, Institute for the Study of Labor (IZA) and DIW

University of Bonn, IZA, CEPR and DIW

Swarthmore College and IZA

University of St. Gallen, IZA, CEPR and DIW

(C) The Author(s). Journal compilation (C) Royal Economic Society 2009 


\section{References}

Akerlof, G. (1982). 'Labor contracts as a partial gift exchange', Quarterly Journal of Economics, vol. 97, pp. 543-69.

Becchetti, L. and Degli, A. G. (2007). 'Measuring the warm glow: players' behaviour self declared happiness in trust game experiments', CEIS Working Paper No. 263.

Bénabou, R. and Tirole, J. (2006). 'Incentives and prosocial behavior', American Economic Review, vol. 96(5), pp. 1652-78.

Berg, J., Dickhaut, J. and McCabe, K. (1995). 'Trust, reciprocity and social history', Games and Economic Behaviour, vol. 10, pp. 122-42.

Bewley, T. (1999). Why Wages Don't Fall During Recessions, Cambridge, MA: Cambridge University Press.

Bowles, S. and Gintis, H. (1998). 'The evolution of strong reciprocity', Research in Economics 98-08-073e, Santa Fe Institute.

Bowles, S. and Gintis, H. (2002). 'The inheritance of inequality', Journal of Economic Perspectives, vol. 16(3), pp. 3-30.

Bowles, S. and Gintis, H. (2004). 'The evolution of strong reciprocity: cooperation in heterogeneous populations', Theoretical Population Biology, vol. 65, pp. 17-28.

Brown, M., Falk, A. and Fehr, E. (2004). 'Relational contracts and the nature of market interactions', Econometrica, vol. 72, pp. 747-80.

Camerer, C. and Thaler, R. (1995). 'Ultimatums, dictators, and manners', Journal of Economic Perspectives, vol. 9, pp. 209-19.

Card, D. and Krueger, A. (1995). Myth and Measurement, The New Economics of the Minimum Wage. Princeton, Princeton University Press.

Carpenter, J. and Seki, E. (2005). 'Do social preferences increase productivity? Field experimental evidence from fishermen in Toyama Bay', IZA Discussion Paper No. 1697.

Clark, A., Masclet, D. and Villeval, M.-C. (2006). 'Effort and comparison income: Experimental and survey evidence', IZA Discussion Paper No. 2169.

Dohmen, T., Falk, A., Huffman, D. and Sunde, U. (2008). 'Representative trust and reciprocity: prevalence and determinants', Economic Inquiry, vol. 46(1), pp. 84-90.

Falk, A., Fehr, E. and Fischbacher, U. (2005). 'Driving forces behind informal sanctions', Econometrica, vol. 7(6), pp. 2017-30.

Falk, A., Fehr, E. and Zehnder, C. (2006). 'Fairness perceptions and reservation wages - the behavioral effects of minimum wage laws', Quarterly Journal of Economics, vol. 121(4), pp. 1347-81.

Falk, A. and Fischbacher, U. (2006). 'A theory of reciprocity', Games and Economic Behavior, vol. 54(2), pp. 293315.

Falk, A. and Zehnder, C. (2007). 'Discrimination and in-group favoritism in a citywide trust experiment', IZA Discussion Paper No. 2765.

Fehr, E. and Falk, A. (1999). 'Wage rigidities in a competitive incomplete contract market. An experimental investigation', Journal of Political Economy, vol. 107(1), pp. 106-34.

Fehr, E. and Gächter, S. (2000). 'Fairness and retaliation', Journal of Economic Perspectives, vol. 14(3), pp. 15981.

Fehr, E. and Gächter, S. (2002). 'Altruistic punishment in humans', Nature, vol. 415, pp. 137-40.

Fehr, E., Kirchsteiger, G. and Riedl, A. (1993). 'Does fairness prevent market clearing? An experimental investigation', Quarterly Journal of Economics, vol. 108, pp. 437-60.

Frey, B. and Stutzer, A. (2002). 'What can economists learn from happiness research?', Journal of Economic Literature, vol. 40, pp. 402-35.

Gächter, S. and Falk, A. (2002). 'Reputation and reciprocity: consequences for the labour relation', Scandinavian Journal of Economics, vol. 104(1), pp. 1-27.

Gneezy, U. (2003). 'Do high wages lead to high profits? An experimental study of reciprocity using real effort', Discussion Paper University of Chicago.

Güth, W., Schmittberger, R. and Schwarze, B. (1982). 'An experimental analysis of ultimatum bargaining', Journal of Economic Behavior and Organization, vol. 3, pp. 367-88.

Heckman, J. J. and Rubinstein, Y. (2001). 'The importance of noncognitive skills: lessons from the GED testing program', American Economic Review, vol. 91(2), pp. 145-9.

Heckman, J. J., Stixrud, J. and Urzua, S. (2006). 'The effects of cognitive and noncognitive abilities on labor market outcomes and social behavior', Journal of Labor Economics, vol. 24(3), pp. 411-82.

Konow, J. and Earley, J. (2008). 'The hedonistic paradox: is homo economicus happier?', Journal of Public Economics, vol. 92, pp. 1-33.

Krueger, A. and Mas, A. (2004). 'Strikes, scabs and tread separations: labor strife and the production of defective Bridgestone/Firestone tires', Journal of Political Economy, vol. 112(2), pp. 253-89.

Osborne, M. (2005). Personality and the Intergenerational Transmission of Economic Status, Princeton: Princeton University Press.

Perugini, M., Gallucci, M., Presaghi, F. and Ercolani, A. P. (2003). 'The personal norm of reciprocity', European Journal of Personality, vol. 17, pp. 251-83. 
Quervaine, D., Fischbacher, U., Treyer, V., Schellhammer, M., Schnyder, U., Buck, A. and Fehr, E. (2004). 'The neural basis of altruistic punishment', Science, vol. 305, pp. 1254-8.

Rabin, M. (1993). 'Incorporating fairness into game theory', American Economic Review, vol. 83(5), pp. 1281302.

Schupp, J. and Wagner, G. G. (2002). 'Maintenance of and innovation in long-term panel studies the case of the German socio-economic panel (GSOEP)', Allgemeines Statistisches Archiv, vol. 86(2), pp. 163-75.

van Praag, B. M. S. and Ferrer-i Carbonell, A. (2008). Happiness Quantified - A Satisfaction Calculus Approach, Oxford: Oxford University Press.

Wagner, G. G., Burkhauser, R. V. and Behringer, F. (1993). 'The English language public use file of the German socio-economic panel', Journal of Human Resources, vol. 28(2), pp. 429-33. 